\title{
Quantitative analysis of effect of neodymium-YAG laser on transplanted mouse carcinomas
}

\author{
WN GARDNER, P HUGH-JONES, MA CARROLL, ER HEWITT, HB HEWITT, \\ W WHIMSTER
}

From the Chest Unit and Department of Surgery and Morbid Anatomy, King's College Hospital Medical School, London

\begin{abstract}
Intradermally transplanted non-immunogenic murine carcinomas measuring 3-6 mm in diameter were exposed to a neodymium-YAG laser beam $(1060 \mathrm{~nm})$ over a range of exposure times (0.5-6 seconds) and energy densities (expressed as watts $/ \mathrm{mm}^{2}$ exposure field). Subsequent growth of the irradiated tumours was compared with that of untreated tumours. A clear doseresponse relationship dependent only on power delivered per unit area was found. Below a given dose threshold (about 2 joules $/ \mathrm{mm}^{2}$ ) the tumours continued to grow at the same rate as the control tumours although an effect of irradiation could be seen histologically. Above this threshold the tumours completely disappeared but by 10-14 days started to regrow at a rate slightly greater than in the control mice; the reason for this increased rate remains to be determined. At the highest doses (above about 5.5 joules $/ \mathrm{mm}^{2}$ ) there was complete regression and skin healing, with no evidence of local recurrence in seven animals and with no evidence of distant metastases in six out of seven up to 12 months later, a result not previously achieved by surgical excision. The laser provides a controlled and simply applied method of tumour eradication. This animal model gives a quantitative basis for further studies of the effects of laser irradiation on tumour growth.
\end{abstract}

Laser irradiation, a monochromatic and coherent source of light energy, has been used for some years in man as one form of treatment for different tumours, including those of the skin, ${ }^{1}$ bladder, ${ }^{2}$ stomach, ${ }^{3}$ and bronchus. ${ }^{4}$ In three studies, ${ }^{2-4}$ the irradiation was applied via an endoscope. Generally the dosage and mode of application of the laser has been determined by trial and error.

While there is extensive information on the biological effects of light ${ }^{56}$ the mechanism of laser action on tumours has not been determined. Thermal denaturation of tissue protein, local occlusion of vascular channels, ${ }^{78}$ selective enzyme changes, and the induction of toxic substances by the cell ${ }^{9}$ may be concerned. Energy transmission to the tissue cells is modified by tissue density, elasticity, fluid content, blood supply, and reflectivity of the skin overlying the tumour; quantitation is therefore difficult. Studies on animal models using pulsed ruby and

Address for reprint requests: Dr P Hugh-Jones, Chest Unit, King's College Hospital Medical School, Denmark Hill, London SE5 8RX. neodymium laser ${ }^{1011}$ gave conflicting and largely qualitative results.

Apart from any possible specific effects on tumour cells, the advantages of the laser include ease of application and the ability to apply a precisely measurable and uniform energy dose to a specific field. This latter property is often not fully used as the laser is usually applied to the tumour in a random punctate fashion, the endpoint being visible blanching of tumour and surrounding tissue. A more quantitative approach is required.

The Medilas MMB continuous solid phase Nd-YAG (yttrium aluminium garnet) laser (Brocades GB Ltd, West Byfleet, Surrey) produces a slightly divergent beam that can be applied for a period ranging from a half a second to many seconds; it gives both volume heating and deep penetration of tissue and has a wavelength of $1060 \mathrm{~nm}$ in the infrared range. By altering the distance from the tumour the field size can be varied to give a uniform coverage of whole tumour beds up to about $2 \mathrm{~cm}$ in diameter, the energy supplied being modified by variations of wattage and exposure time.

In the present study the effect of neodymium- 
YAG laser irradiation on the growth of an intradermal, non-immunogenic mouse tumour has been described and quantitated. This study is proceeding in parallel with clinical studies of the endoscopic application of the same laser to bronchial tumours.

\section{Methods}

Pilot experiments with hairless mice showed that at doses of 20-60 watts maintained for $0 \cdot 5-2$ seconds the laser produced ulcers of variable thickness that healed within a week. This enabled us to judge the order of dosage to be given to the tumour-bearing mice.

The tumour, WHT adenocarcinoma N-C, was of spontaneous origin in the breast and in the present experiments was transplanted on to 2-4-month-old WHT/Ht mice of either sex. It is moderately well differentiated, has given no evidence of immunogenicity in the mouse substrain used here, and frequently metastasises..$^{1314} \mathrm{~A}$ tumour cell suspension was prepared as described by Hewitt, ${ }^{14}{ }^{15}$ and groups of mice had about $2 \times 10^{5}$ cells suspended in $0.02 \mathrm{ml}$ injected under ether anaesthesia into the dermis of the left flank. Tumours grew as discrete plaques with no extension deep to the corium and by the seventh day after injection, when the laser irradiation was performed, they measured 3-6 $\mathrm{mm}$ in diameter.

Forty-three mice were divided into groups of nine, 12,10, and 12, each group being irradiated on a different day. Fourteen animals randomly chosen from these groups were left unirradiated to serve as controls. Mice for irradiation were very lightly anaesthetised by subcutaneous injection of a saline solution of tribromoethanol (Avertin, Winthrop), the skin round the tumour was shaved, and a fold of skin bearing the tumour was retracted from the abdominal wall and held in the beam with the fingers.

In the first two groups, the tumours were $7 \mathrm{~cm}$ from the end of the hand piece, the field being 5.5 $\mathrm{mm}$ in diameter. Pairs of tumour-bearing mice were exposed for 2 seconds at $20,40,60,80$, or 100 watts; two pairs were exposed for 0.5 and 1 second at 20 watts. In the third and fourth groups the dis-

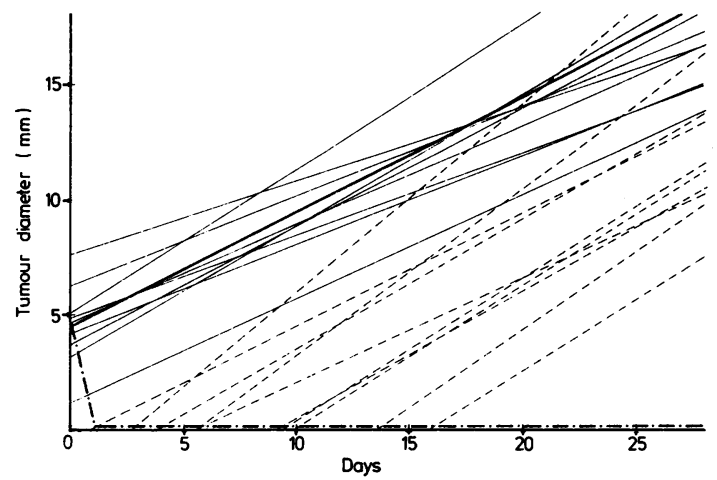

Growth or regrowth curves of tumours: unirradiated tumours, $\longrightarrow$ (mean line shown, $n=14)$; unaffected tumours receiving an average dose of 1.09 joules $/ \mathrm{mm}^{2}$, (individual results shown); delayed-growth tumours receiving 4.04 joules $/ \mathrm{mm}^{2}$, _ _- (individual results shown); and cured tumours receiving $7 \cdot 15$ joules $/ \mathrm{mm}^{2}$, ----(mean line shown, $n=7)$. The energy delivered per $\mathrm{mm}^{2}$ exposure field was calculated as watts $/ \mathrm{mm}^{2} \times$ $\mathrm{t}($ seconds) $=$ joules. Each individual growth curve is the least-squares regression line through five to nine measurements of tumour diameter.

tance was increased to $11 \mathrm{~cm}$, giving a field size of 9 $\mathrm{mm}$ diameter, and the exposure time was changed to 6 seconds to compensate for the reduced intensity of the exposure. The power was increased in steps from 10 to 80 watts. The area irradiated was known from the visible helium-neon excitant light set up to coincide with the infrared beam. To determine the total energy absorbed per unit area field the total wattage was divided by the irradiation field area and multiplied by time.

After irradiation any residual tumour could be detected by palpation, and its further growth was documented by measurement and photography. Animals were killed when the diameter reached about $15 \mathrm{~mm}$.

\section{Results}

At all dose levels the immediate response to irradiation was unimpressive. No direct burning occurred.

Growth of control and laser-treated tumours (means $\pm S E M$ )

The lines for the control and unaffected groups are interchangeable but differ appreciably in position (and to a lesser extent slope-see text) from the line of the delayed-growth group.

\begin{tabular}{|c|c|c|c|c|}
\hline Tumour group & $\begin{array}{l}\text { No of } \\
\text { experiments }\end{array}$ & $\begin{array}{l}\text { Laser dose } \\
\left(\mathrm{J} / \mathrm{mm}^{2}\right)^{*}\end{array}$ & $\begin{array}{l}\text { Regression slope } \dagger \\
\text { of growth curve ( } \mathrm{mm} \\
\text { diameter/day) }\end{array}$ & $x$-axis intercept $\dagger$ \\
\hline $\begin{array}{l}\text { Unirradiated } \\
\text { Laser-unaffected } \\
\text { Laser-delayed growth } \\
\text { Laser-cured }\end{array}$ & $\begin{array}{r}14 \\
9 \\
10 \\
7\end{array}$ & $\begin{array}{l}1.09 \pm 0.18 \\
4.04 \pm 0.35 \\
7.15 \pm 0.34\end{array}$ & $\begin{array}{l}0.50 \pm 0.02 \\
0.45 \pm 0.03 \\
0.61 \pm 0.03\end{array}$ & $\begin{array}{r}-9.43 \pm 1 \cdot 15 \\
-10.9 \pm 2 \cdot 12 \\
7.67 \pm 1 \cdot 51\end{array}$ \\
\hline
\end{tabular}

*All differ significantly.

†"Slope" and "Intercept" refer to the least-squares regression relationships of tumour diameter to days after irradiation. 
Depending on the dosage applied, various degrees of blanching were visible in the tissues surrounding the tumour, which remained intact with perhaps slight shrinkage at the higher doses. A little carbonisation occurred if hairs remained in the field. As seen in the figure and table, there were three statistically distinct categories of response, depending largely on the dose level: in the range $0.42-1.89$ joules $/ \mathrm{mm}^{2}$ (nine animals) the growth of exposed tumours was indistinguishable from that of unirradiated tumours; in the range $1 \cdot 89-5.04$ joules $/ \mathrm{mm}^{2}$ (10 animals) there was delay in the resumption of growth; and seven tumours in mice receiving doses in the range $4 \cdot 66-8.4$ joules $/ \mathrm{mm}^{2}$ were eradicated. In this group four mice have so far survived nearly 12 months without local or distant metastases. Of the remaining three, two are still alive and well after two months; one died at six weeks but the cause of death was not determined. (Three mice were excluded from the analysis-see below.)

Tumours whose growth was not delayed by irradiation showed some central necrosis but continued to grow centrifugally at the same rate as control tumours. Both the delayed-growth and cured tumours had disappeared within two days of irradiation, leaving various degrees of ulceration and scar. Thereafter rapid healing occurred, leaving an almost invisible scar in the cured animals.

Recurring tumours presented as small nodules in the centre of the scar, usually first palpable about 10-12 days after exposure, after which they grew at a rate that statistically was slightly greater than that of untreated tumours (table). Further study is required to assess whether this increase is of physiological significance. In three mice recurrences appeared at the periphery of the irradiation field; in all such cases the tumours had been at the upper end of the range of tumour size, suggesting that the exposure field size was inadequate. These mice were excluded from the analysis.

Histology Only recurrent and control tumours were examined. In all cases the tumour was clearly demarcated and did not invade the surrounding or underlying connective tissue; it extended laterally beneath the adjacent skin. In both controls and laser-treated cases there was ulceration of the skin over the tumour and some necrosis of the adjacent tumour. Indeed, the main difference between the control tumours and the laser-treated tumours lay in how deeply the tumour necrosis extended from the ulcerated area: in the controls the necrosis was superficial, but in the laser-treated tumours it frequently extended to the deep aspect of the tumour, although in all cases a layer of viable tumour cells was still present at the deep surface.

\section{Discussion}

In previous studies of this very malignant tumour quite wide surgical excision of similar intradermal tumours was almost always followed, within 70 days, by local recurrence or lymph-node or pulmonary metastasis or both ${ }^{14}$; possibly these sequelae were encouraged by the surgical interference. In the present study therefore the relative absence of local and distant metastases in the cured group was unexpected but encouraging, the response perhaps being due to instant shutdown or coagulation of surrounding blood vessels. ${ }^{17}$ Whether laser treatment is clearly better than diathermy or other forms of local heating remains to be determined. ${ }^{16}$

These results agree with earlier findings by McGuff, who used the pulsed ruby laser applied to autogenous hamster tumours, ${ }^{10}$ but differ from the results of Minton, who, using pulsed ruby and neodymium lasers, found no evidence of ongoing destruction of the Cloudman S91 melanoma after the irradiation. ${ }^{11}$ They are consistent with the good results obtained by Kozlov and Moskalik for the treatment of various benign and malignant skin tumours in man. ${ }^{1}$

The Nd-YAG laser irradiation is characterised by a large penetration depth and deep heating resulting from internal scattering of irradiation (TH Hallsdorssen et al, paper presented to International Medical Laser Symposium, Detroit, 1979). Perhaps therefore all the effect is due to heat, and no specific enzyme changes need be invoked. The resolution of the tumour over the 24-48 hours after irradiation is more difficult to explain; it could represent merely the scavenging of a large mass of dead tumour tissue, or it could suggest that some form of local toxin is produced in the days after irradiation, as suggested by May. ${ }^{9}$

It has been suggested that low-power irradiation over a longer period may be preferable to highpower irradiation over short periods (Hallsdorssen et al, 1979). Our results do not support this conclusion. The effect on the tumour seems to be related to the power delivered per unit area irrespective of the combination of exposure time, wattage, and field area (and hence distance of the hand piece from the tumour) used to calculate this power.

The clear division of the responses into three groups can partly be explained by the geometry of the tumour and the laser beam. In the low-dose group the histological findings suggest that at the edges of the field where the irradiation is weakest a ring of living cells was left that continued to grow outwards at the same rate as in the controls; the lack of a dose relation within this group would suggest that the number of cells surviving is relatively unim(n) 0 $\overrightarrow{\vec{\omega}}$ 
portant. The intermediate group received sufficient irradiation to destroy all these peripheral cells (except when the field size was inadequate), but some cells could have remained alive in the base of the tumour and given rise to recurrences. Finally, in the group with the total cure all cells were presumably eradicated.

These results show that the Nd-YAG laser can efficiently eradicate small superficial carcinomas with properties similar to those of naturally occurring carcinomas in man. If we may speculate from these results, it seems that the Nd-YAG laser could be used endoscopically in man to eradicate and control haemoptysis from small, centrally placed bronchial squamous carcinomas not amenable to surgery, or to reduce the tumour mass in the case of undifferentiated carcinomas treated by chemotherapy.

This tumour model can also provide a suitable means of showing the effects of different frequencies of laser light on tumour cells made more frequency specific by dyes or drugs.

\section{References}

${ }^{1}$ Kozlov AP, Moskalik KG. Pulsed laser radiation therapy of skin tumours. Cancer 1980;46:2172-8.

${ }^{2}$ Staehler Von G, Schmiedt E, Hofstetter A. Destruction of bladder tumours using transurethral neodymiumYAG laser irradiation. Helv Chir Acta 1978;45:30711.

${ }^{3}$ Rosch W, Fruhmorgen P. Endoscopic treatment of precancerous and early gastric carcinoma. Endoscopy 1980;12:109-13.

${ }^{4}$ Toty L, Personne C, Colchen A, Vourch G. Bronchoscopic management of tracheal lesions using the neodymium yttrium aluminium garnet laser. Thorax 1981;36:175-8.

${ }^{5}$ Smith KC. Common misconceptions about light; photobiology of ultraviolet radiation. In: Pratesi; RC, Sac- chi SC, eds. Lasers in photomedicine and photobiology. Berlin: Springer-Verlag, 1980:23-5, 40-7.

- Giese AC. Basic photobiology and open problems. In: Pratesi RC, Sacchi SC, eds. Lasers in photomedicine and photobiology. Berlin: Springer-Verlag, 1980:26-39.

${ }^{7}$ Mihashi S. Immediate effects of $\mathrm{CO}_{2}$ laser irradiation on soft tissue. J Otolaryngol Jpn 1976;79:1341-6.

${ }^{8}$ Moskalik KG, Lipova VA, Neishtadt EL. Morphological changes of skin tumours induced by pulse laser radiation. Arkh Patol 1979;41:12-7.

9 May JF, Rounds DE, Cone CD. Intercellular transfer of toxic components after laser irradiation. $J$ Natl Cancer Inst 1971;46:655-63.

${ }^{10}$ McGuff PE, Deterling RA Jr, Bushnell D, Gottlieb LS, Rocker F, Fahimi HD. Laser radiation of malignancies. Ann NY Acad Sci 1965;122:747-57.

${ }^{11}$ Minton JP, Zelen M, Ketcham AS. Experimental results from exposure of Cloudman S-91 melanoma in the COBA/ZF, hybrid mouse to neodymium or ruby laser radiation. Ann NY Acad Sci 1965;122:758-66.

${ }^{12}$ Hugh-Jones P, Costello J, Whimster W. Management and treatment of lung cancer: possible uses of lasers. Thorax 1979;34:696.

${ }^{13}$ Hewitt HB, Blake ER, Walder AS. A critique of the evidence for active host defence against cancer based on personal studies of 27 murine tumours of spontaneous origin. Br J Cancer 1976;33:241-59.

${ }^{14}$ Hewitt HB, Blake ER. Failure of pre-operative $C$ parvum vaccine to modify secondary disease following excision of two non-immunogenic murine carcinomas. Br J Cancer 1978;38:219-23.

15 Hewitt HB. The effect on cell survival of inhalation of oxygen under high pressure during irradiation in vivo of a solid mouse sarcoma. Br J Radiol 1966;39:19-24.

${ }^{16}$ Ehlers G, Florian HJ. Do laser rays have a carcinogenic action? Cytophotometric studies on the DNA content of the epidermis after exposure to laser rays. Fortschr Med 1973;91:832-4.

${ }^{17}$ Hewitt HB, Blake ER. Further studies of the relationship between lymphatic dissemination and lymphnodal metastases in non-immunogenic murine tumours. Br J Cancer 1977;35:415-9. 